\title{
Production of Cellulase by Microbulbifer hydrolyticus through Co-fermentation of Glucose and Xylose from Lignocellulose
}

\author{
Huan Liu,,${ }^{\mathrm{a}, \mathrm{b}, 1}$ Xiaolan Huang, ${ }^{\mathrm{a}, 1}$ Qi Xiao, ${ }^{\mathrm{a}}$ Yue Yu, ${ }^{\mathrm{a}}$ Li Deng, $,{ }^{\mathrm{a}, \mathrm{b}}, *$ and Fang Wang ${ }^{\mathrm{a}}$ \\ Cellulase is a compound enzyme that catalyzes cellulose into \\ monosaccharides or oligosaccharides. Large amounts of cellulase are \\ needed with the development of the lignocellulose processing industry, \\ which necessitates faster methods to produce cellulase. In this work, the \\ marine bacterium Microbulbifer hydrolyticus IRE-31-192 was selected to \\ produce cellulase, due to its fast growth rate and short high space-time \\ yield. Co-fermentation of glucose and xylose to produce cellulase was \\ investigated on the basis of previous work. When the ratio of \\ glucose/xylose was 2:1 (w/w), $294 \mathrm{U} / \mathrm{L}$ cellulase activity with highest \\ space-time yield of $12.2 \mathrm{U} / \mathrm{L} \mathrm{h}$ was obtained. The hydrolytic liquid of \\ lignocellulose prepared from dried distiller's grains with solubles (DDGS) \\ with the similar ratio of glucose/xylose was used as medium to produce \\ cellulase. The efficiency of cellulase production from processed and \\ unprocessed hydrolysates of DDGS was compared. Unprocessed \\ hydrolysates were more beneficial for the production of cellulase, such that \\ its activity was $261 \mathrm{U} / \mathrm{L}$ with a space-time yield of $14.5 \mathrm{U} / \mathrm{L} \mathrm{h}$. Thus, \\ commonly used pure glucose and xylose could be replaced by \\ hydrolysates of DDGS, and marine bacteria has potential application for \\ cellulase production.
}

Keywords: Cellulase; Dried distiller's grains with solubles; Marine bacteria; Lignocellulose;

Contact information: a: Beijing Bioprocess Key Laboratory, State Key Laboratory of Chemical Resource Engineering, Beijing University of Chemical Technology, Beijing, 100029, PR China; $b$ : Amoy - BUCT Industrial Bio-technovation Institute, Amoy, 361022, PR China; 1: the first two author make the same contribution to this work; *Corresponding author: dengli@ mail.buct.edu.cn

\section{INTRODUCTION}

Global energy demand and fossil fuel depletion has intensified the need for alternative energy sources (Zhang et al. 2013). Lignocellulosic biomass is a significant renewable resource available worldwide for the production of sustainable biofuels and bioproducts at competitive prices (Wen et al. 2013; Liu et al. 2015). A large market potential for cellulase production is projected due to its capability of converting lignocellulosic biomass to fermentable sugars for the production of high value chemicals, which has required faster methods to improve its productivity (Silva and Filho 2017).

Cellulases can be produced from both fungi and bacteria. Fungi show a higher enzyme performance but require a long growth cycle (Bansal et al. 2014; Payne et al. 2015). Bacterial production of cellulase has drawn much attention due to its fast growth rate and high space-time yield as well as the potential for scalable production (Dias et al. 2015; Paudel and Qin 2015). Microbulbifer hydrolyticus IRE-31 (ATCC 700072) is a marine bacterium isolated from marine pulp mill effluents that can grow in high salinity medium. It was identified in a previous study (Arens and Liu 2013). It has fast and strong 
growth ability. Carbon sources are an energy source for the bacterial strain and essential inducers for cellulase production (González et al. 1997). In a previous study, the hydrolysis rate of carboxymethyl-cellulase (i.e. CMCase assay) was used to represent the activity of cellulase, and the effect of various carbon sources on cellulase production by Microbulbifer hydrolyticus IRE-31 was explored (Liu et al. 2019). CMCase activities of 473 U/L and 266 U/L were obtained from glucose and xylose, respectively. However, commonly used glucose was mostly obtained from starch sources, which is expensive for industrial utilization, and it directly competes with human food. Hence, an accessible and cheaper carbon source needs to be explored.

Hydrolytic liquid from lignocellulose that contains both glucose and xylose is a substitute for common carbon resources to produce biochemicals (Guerriero et al. 2016), and thus was selected as an available carbon source to investigate its capability in cellulase production. The hydrolytic liquid prepared from dried distiller's grains with solubles (DDGS) as the lignocellulosic waste in wine production is used as a protein feedstuff in livestock, but the high fiber content in DDGS limits their utilization as livestock feeding because of possible health problems (Avelar et al. 2010). According to Liu et al. (2017b), DDGS contains glucose and xylose, but it has a high level of crude protein from yeast residue. The hydrolytic liquid of DDGS could be used to produce high value-added chemicals including ethanol, fumaric acid, etc. Therefore, it could be used to produce cellulase as well.

In this work, the co-fermentation process of glucose and xylose to produce cellulase was studied. The effect of hydrolytic liquid from DDGS on the production of cellulase was investigated.

\section{EXPERIMENTAL}

\section{Preparation of the Hydrolytic Liquid}

The DDGS was obtained from Shan Xi Xing Hua Cun wine factory and was used to prepare the hydrolytic liquid through acid hydrolysis, where the yields of monosaccharides reached $258 \mathrm{mg} / \mathrm{g}$ DDGS, including $15.88 \mathrm{~g} / \mathrm{L}$ glucose, $7.53 \mathrm{~g} / \mathrm{L}$ xylose, $2.35 \mathrm{~g} / \mathrm{L}$ arabinose, and $0.116 \mathrm{~g} / \mathrm{L}$ furfural. As Microbulbifer hydrolyticus IRE-31-192 is a marine bacterium isolated from marine pulp mill effluents, it could tolerate inhibitors and high-concentrations of salt. Therefore, various DDGS hydrolytic liquids were prepared for cellulase production.

The hydrolysate from DDGS was first neutralized with $\mathrm{Ca}(\mathrm{OH})_{2}$ to $\mathrm{pH} 7$ and then adsorbed with active carbon; this product was defined as processed-hydrolytic liquid after being filtrated (Schuster and Chinn 2013; Liu et al. 2017b). The product neutralized with $\mathrm{KOH}$ to $\mathrm{pH} 7$ without any other pretreated process was defined as unprocessed-hydrolytic liquid (Liu et al. 2018).

\section{Microorganism and Culture Medium}

Microbulbifer hydrolyticus IRE-31-192 from the authors' laboratory was used in this study. The strain was maintained on $2216 \mathrm{E}$ agar slant culture medium kept away from light by periodic transfers following incubation at $37{ }^{\circ} \mathrm{C}$ for $12 \mathrm{~h}$ to $18 \mathrm{~h}$ (Yiheng Instrument Co. Ltd, Shanghai, China) and storing at $4{ }^{\circ} \mathrm{C}$. The medium $2216 \mathrm{E}$ was purchased from Qingdao Nissui Biotechnology Co. Ltd. (Qingdao, China). It is a special culture medium for marine bacteria, containing (per liter): peptone $(5 \mathrm{~g})$, yeast extract (1 
g), ferric citrate $(0.1 \mathrm{~g})$, sodium chloride (19.45 g), magnesium chloride $(5.9 \mathrm{~g})$, magnesium sulfate $(3.24 \mathrm{~g})$, calcium chloride $(1.8 \mathrm{~g})$, potassium chloride $(0.55 \mathrm{~g})$, sodium bicarbonate $(0.16 \mathrm{~g})$, potassium bromide $(0.08 \mathrm{~g})$, strontium chloride $(0.034 \mathrm{~g})$, boric acid $(0.022 \mathrm{~g})$, sodium silicate $(0.004 \mathrm{~g})$, sodium fluoride $(0.0024 \mathrm{~g})$, ammonium nitrate $(0.0016 \mathrm{~g})$, and disodium hydrogen phosphate $(0.008 \mathrm{~g})$. The composition of agar medium was (per liter): $37.4 \mathrm{~g} 2216 \mathrm{E}$, and $20 \mathrm{~g}$ agar, which was also used as seed medium without agar. The composition of the common fermentation medium was (per liter): $37.4 \mathrm{~g} 2216 \mathrm{E}$, glucose, and xylose. When the hydrolytic liquid of DDGS was used as fermentation medium, the other nutrient was avoided. All media were sterilized by autoclaving at $116^{\circ} \mathrm{C}$ for $25 \mathrm{~min}$.

\section{Fermentation Process}

A single colony of strain Microbulbifer hydrolyticus IRE-31-192 grown on agar slant culture medium was selected and cultured using seed culture liquid. It was then kept away from light for $12 \mathrm{~h}$ at $37^{\circ} \mathrm{C}$ and $180 \mathrm{rpm}$. A 5\% (v/v) seed culture liquid was added into a $250 \mathrm{~mL}$ flask with $50 \mathrm{~mL}$ fermentation medium, which was then incubated for $3 \mathrm{~h}$ in a rotary shaker (Taicang instrument Co. Ltd, Jiangsu, China) at $37{ }^{\circ} \mathrm{C}$ and $180 \mathrm{rpm}$.

The use of the strain M. hydrolyticus IRE-31-192 in co-fermentation of glucose and xylose was subsequently investigated. The total sugar content was $30 \mathrm{~g} / \mathrm{L}$ and the ratio of glucose was gradually decreased with the addition of xylose. The proportions of glucose and xylose (glucose/xylose (w/w): 5:1, 2:1, and 1:1) were investigated with the aim of optimization and highest production of CMCase. As the optimum proportion of glucose/xylose was studied in the co-fermentation process, the capability of $M$. hydrolyticus IRE-31-192 to produce CMCase from processed and unprocessed hydrolysates of DDGS was finally investigated. The fermentation broth was sampled at different times from the shake flask and centrifuged at $4{ }^{\circ} \mathrm{C}$ and $9,000 \times \mathrm{g}$ for $15 \mathrm{~min}$ (Yancheng instrument Co. Ltd, Jiangsu, China). The supernatant was used to measure the CMCase activity.

\section{Analysis Methods}

The biomass was analyzed using UV spectrophotometry (Meipuda instrument Co. Ltd, Shanghai, China) at $600 \mathrm{~nm}$ with results ranging from $0.1 \mathrm{~A}$ to $0.8 \mathrm{~A}$. CMCase activity was defined as the amount of cellulase enzyme that liberates $1.0 \mu \mathrm{mol}$ of reducing sugar (glucose) per minute under the assay conditions of $\mathrm{pH} 7.0$ at $50{ }^{\circ} \mathrm{C}$ (Singh et al. 2015). The CMCase activity in fermentation broth was thus expressed with enzyme activity per liter of fermentation broth (U/L).

The reducing sugar content was determined by the 3,5-dinitrosalicylic acid solution method (DNS reagent) for color development and the absorbance was measured at $540 \mathrm{~nm}$ (Hu et al. 2008). The consumption of glucose and xylose in fermentation process were quantified by high-performance liquid chromatography (HPLC) with a Bio-Rad Aminex HPX-87 H ion exclusion column (Beijing, China) with a refractive index detector and UV detector at $210 \mathrm{~nm}$.

The column was eluted with $0.005 \mathrm{M} \mathrm{H}_{2} \mathrm{SO}_{4}$ at a column temperature of $50{ }^{\circ} \mathrm{C}$ and a flow rate of $0.6 \mathrm{~mL} / \mathrm{min}$ (Liu et al. 2017a). The p-values of the data shown in this work were $\mathrm{p}<0.05$ after significance testing. 


\section{RESULTS AND DISCUSSION}

\section{CMCase Production from Co-fermentation of Glucose and Xylose}

Liu et al. (2019) showed that high CMCase activities were obtained from a mixture of $30 \mathrm{~g} / \mathrm{L}$ glucose and $10 \mathrm{~g} / \mathrm{L}$ xylose. Based on this result, the CMCase production from co-fermentation process of glucose and xylose was investigated using $30 \mathrm{~g} / \mathrm{L}$ mixture as carbon source. As shown in Fig. 1, when the content of glucose was decreased, the CMCase activity was reduced.
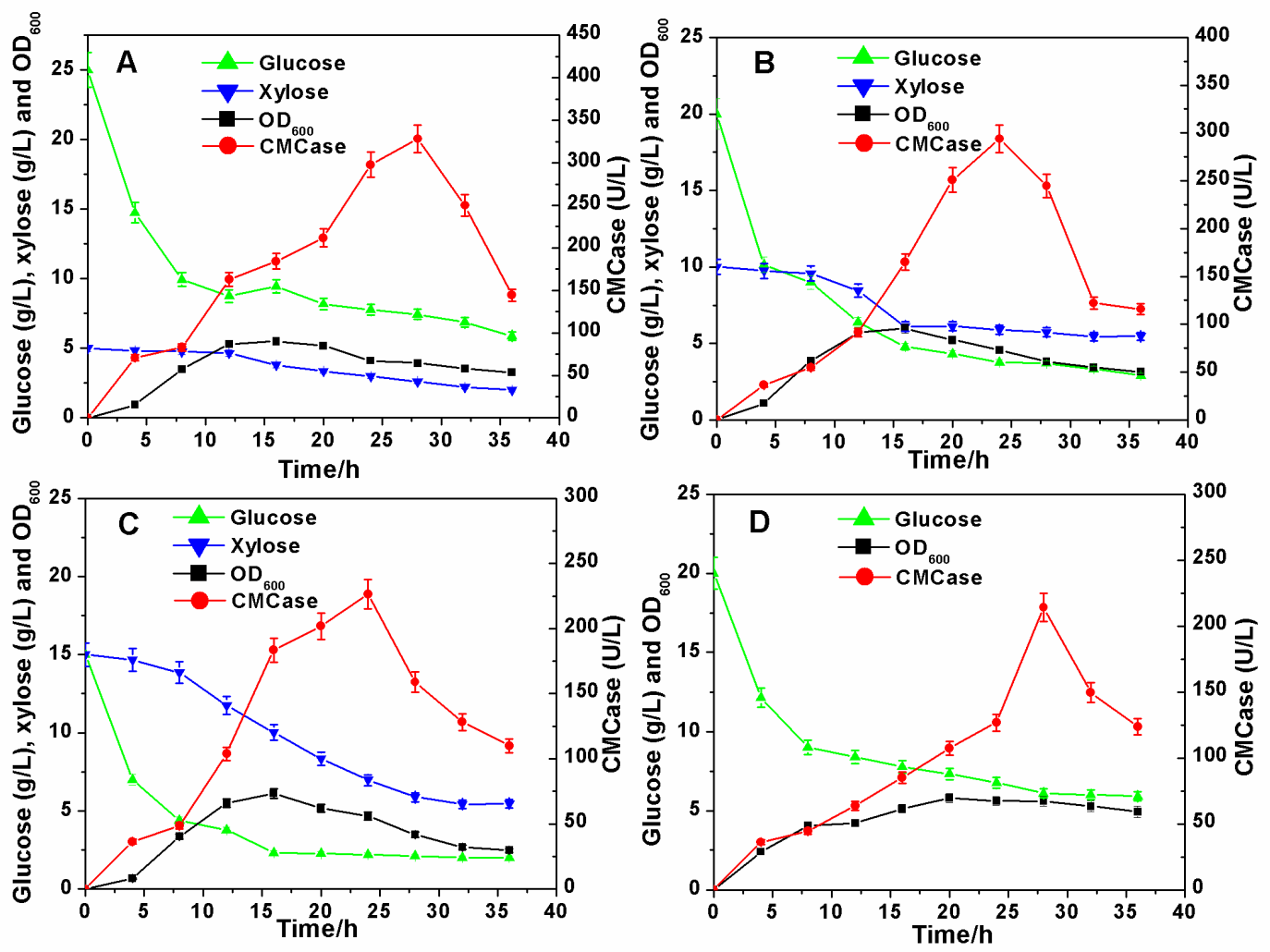

Fig. 1. The effect of different glucose/xylose ratio on the cellulase production process. (A: glucose/xylose 5:1 (w/w); B: glucose/xylose 2:1 (w/w); C: glucose/xylose 1:1 (w/w); and D: $20 \mathrm{~g} / \mathrm{L}$ glucose)

When $25 \mathrm{~g} / \mathrm{L}$ glucose and $5 \mathrm{~g} / \mathrm{L}$ xylose were co-fermented (Fig. 1A), the highest CMCase activity reached up to $328 \mathrm{U} / \mathrm{L}$, while 294 and $226 \mathrm{U} / \mathrm{L}$ CMCase activities were achieved after the ratio of glucose/xylose were decreased to 2:1 (Fig. 1B) and 1:1 (Fig. 1C), respectively. These findings indicated that glucose was beneficial for the production of CMCase. However, even though the CMCase activity decreased with the addition of xylose, the increasing OD600 value demonstrated that xylose was helpful for cell growth. An appropriate cell growth could enhance the cellulase accumulation rate. Therefore, in comparison of the volumetric productivity, the highest value of $12.25 \mathrm{U} / \mathrm{L} \mathrm{h}$ was obtained in co-fermentation of $20 \mathrm{~g} / \mathrm{L}$ glucose and $10 \mathrm{~g} / \mathrm{L}$ xylose, which was similar to the results obtained in previous work using glucose $(16.85 \mathrm{U} / \mathrm{L} \mathrm{h})$ or xylose $(16.6 \mathrm{U} / \mathrm{L} \mathrm{h})$ as solo carbon source, respectively (Liu et al. 2019). As shown in Fig. 1D, when 20 g/L glucose was used as solo carbon source, the $\mathrm{OD}_{600}$ increased more slowly than it did in a cofermentation process, yielding to 214 U/L CMCase activities. This showed that the addition 
of xylose could improve the fermentation process, owning to that an optimum content of xylose benefited to reach a suitable cell growth, leading to an enhancement of CMCase production. Therefore, $20 \mathrm{~g} / \mathrm{L}$ glucose and $10 \mathrm{~g} / \mathrm{L}$ xylose was the optimum addition level in co-fermentation process.

\section{CMCase Production from Hydrolytic Liquid of Lignocellulose}

The original hydrolytic liquid prepared from DDGS contained $15.9 \mathrm{~g} / \mathrm{L}$ glucose, $7.53 \mathrm{~g} / \mathrm{L}$ xylose, and 7.16 g/L crude protein (Liu et al. 2017b), which was pretreated using the above mentioned method to obtain both processed and unprocessed hydrolytic liquids, respectively. The content of processed hydrolytic liquid changed to $12.6 \mathrm{~g} / \mathrm{L}$ glucose, 6.25 $\mathrm{g} / \mathrm{L}$ xylose, and $5.39 \mathrm{~g} / \mathrm{L}$ crude protein. The ratio of glucose/xylose was almost 2:1 in both kind of hydrolytic liquids similar to that in the optimum co-fermentation process, and they were used as medium to investigate the effect on the production of CMCase, as shown in Fig. 2. When the unprocessed hydrolytic liquid was used as medium (Fig. 2A), the highest CMCase activity reached $261 \mathrm{U} / \mathrm{L}$ at $18 \mathrm{~h}$ with the volumetric productivity of $14.5 \mathrm{U} / \mathrm{L}$ per hour, which was higher than that got from processed hydrolytic liquid $(11.31 \mathrm{U} / \mathrm{L} \mathrm{h})$. Meanwhile, OD 600 of the strain in both hydrolytic liquids also showed the same trend that it was higher in unprocessed hydrolytic liquid. It was presumed that the content of sugar in unprocessed hydrolytic liquid was higher than it was in the processed liquid, and that the unprocessed hydrolytic liquid with high-concentration of salt ions was more suitable for the strain to grow as well as to produce CMCase. In addition, the CMCase activities and its volumetric productivity obtained from unprocessed DDGS hydrolytic was similar with the value of the co-fermentation process, which meant that the hydrolytic liquid of lignocellulose could significantly replace the common carbon sources for producing cellulase.
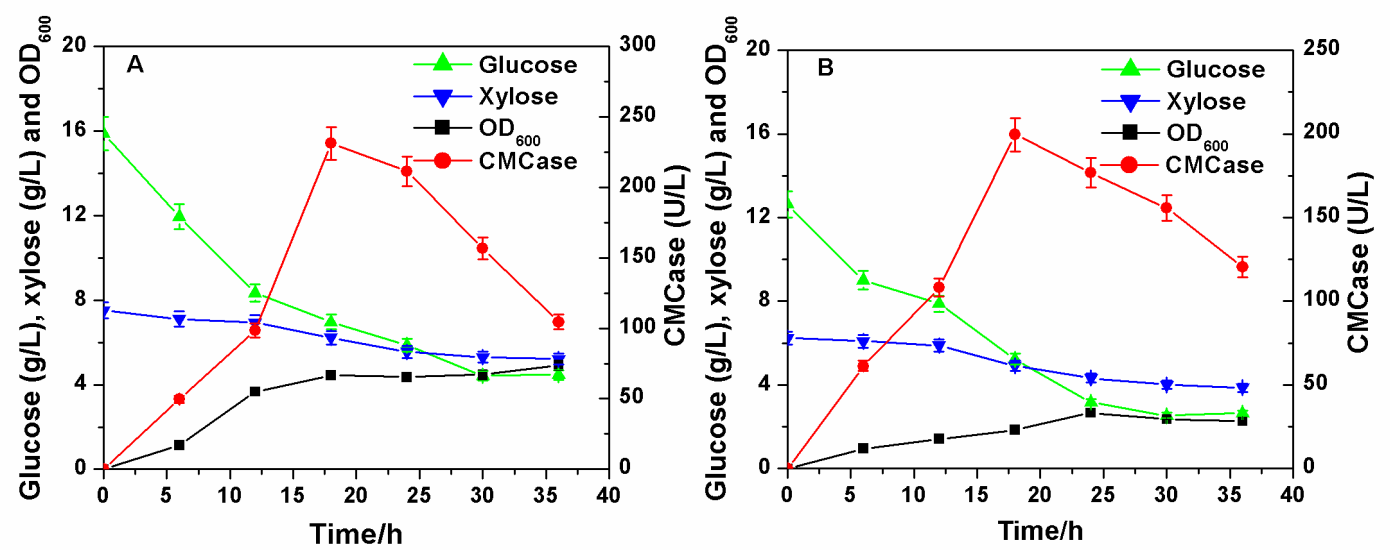

Fig. 2. The effect of unprocessed and processed hydrolytic liquid on the production of cellulase (A: unprocessed hydrolytic liquid; and B: processed hydrolytic liquid)

\section{CONCLUSIONS}

1. Marine bacteria Microbulbifer hydrolyticus IRE-31-192 was selected to investigate the production of cellulase using co-fermentation of a mixture of glucose and xylose. A cellulase activity of $293 \mathrm{U} / \mathrm{L}$ was obtained from the mixture with a glucose/xylose ratio 
of $2: 1(\mathrm{w} / \mathrm{w})$.

2. The hydrolytic liquid of lignocellulose, prepared from dried distiller's grains with solubles (DDGS) with a similar glucose/xylose ratio, was used as medium to produce cellulase using $M$. hydrolyticus IRE-31-192. The highest CMCase activity reached $261.3 \mathrm{U} / \mathrm{L}$ at $18 \mathrm{~h}$ with the volumetric productivity of $14.52 \mathrm{U} / \mathrm{L} \mathrm{h}$, when the unprocessed hydrolytic liquid was used as medium.

3. Unprocessed hydrolytic liquid with high content of monosaccharide and salt ions was more beneficial for the celllase production process, which meant that the hydrolytic liquid of lignocellulose had a major potential utilization to replace common carbon sources in the cellulase production process.

\section{ACKNOWLEDGMENTS}

This research was financially supported by National Key Research Program (2016YFD0400601, 2017YFB0306800, 2017YFD0400603, and 2017YFB0306801, 2017YFB0306904), National Natural Science Foundation of China (21978017), China postdoctoral science foundation (2019M660420), and the Amoy Industrial Biotechnology R\&D and Pilot Conversion Platform (3502Z20121009).

\section{REFERENCES CITED}

Arens, K., and Liu, S. (2013). "Induction of cellulase production by Microbulbifer hydrolyticus with hot-water wood extract," J. Biopro. Eng. Biorefin. 2(4), 262-270(9). DOI: 10.1166/jbeb.2013.1060

Avelar, E., Jha, R., Beltranena, E., Cervantes, M., Morales, A., and Zijlstra, R. T. (2010). "The effect of feeding wheat distillers dried grain with solubles on growth performance and nutrient digestibility in weaned pigs," Anim. Feed Sci. Tech. 160 (12), 73-77. DOI: 10.1016/j.anifeedsci.2010.06.009

Bansal, N., Janveja, C., Tewari, R., Soni, R., and Soni, S. K. (2014). "Highly thermostable and $\mathrm{pH}$-stable cellulases from Aspergillus niger NS-2: properties and application for cellulose hydrolysis," Appl. Biochem. Biotechnol. 172(1), 141-156. DOI: $10.1007 / \mathrm{s} 12010-013-0511-9$

Dias, M., Melo, M., Schwan, R., and Silva, C. (2015). "A new alternative use for coffee pulp from semi - dry process to $\beta$-glucosidase production by Bacillus subtilis," Lett. Appl. Microbiol. 61(6), 588-595. DOI: 10.1111/lam.12498

González, J. M., Mayer, F., Moran, M. A., Hodson, R. E., and Whitman, W. B. (1997). "Microbulbifer hydrolyticus gen. nov., sp. nov., and Marinobacterium georgiense gen. nov., sp. nov., two marine bacteria from a lignin-rich pulp mill waste enrichment community," Inter. J. Syst. Bacteriol. 47(2), 369-376. DOI: 10.1099/00207713-47-2369

Guerriero, G., Hausman, J. -F., Strauss, J., Ertan, H., and Siddiqui, K. S. (2016). "Lignocellulosic biomass: Biosynthesis, degradation, and industrial utilization," Eng. Life Sci., 16(1), 1-16. DOI: 10.1002/elsc.201400196

Hu, R., Lin, L., Liu, T., Ouyang, P., He, B., and Liu, S. (2008). "Reducing sugar content in hemicellulose hydrolysate by DNS method: A revisit," J. Biobased Mater. Bio. 
2(2), 156-161. DOI: 10.1166/jbmb.2008.306

Liu, H., Hu, H., Jin, Y., Yue, X., Deng, L., Wang, F., and Tan, T. (2017a). "Cofermentation of a mixture of glucose and xylose to fumaric acid by Rhizopus arrhizus RH 7-13-9\#," Bioresource Technol. 233, 30-33. DOI: 10.1016/j.biortech.2017.02.035

Liu, H., Wang, W., Deng, L., Wang, F., and Tan, T. (2015). "High production of fumaric acid from xylose by newly selected strain Rhizopus arrhizus RH 7-13-9\#," Bioresource Technol. 186, 348-350. DOI: 10.1016/j.biortech.2015.03.109

Liu, H., Yue, X., Jin, Y., Wang, M., Deng, L., Wang, F., and Tan, T. (2017b). "Preparation of hydrolytic liquid from dried distiller's grains with solubles and fumaric acid fermentation by Rhizopus arrhizus RH 7-13," J. Environ. Manage. 201, 172-176. DOI: 10.1016/j.jenvman.2017.05.054

Liu, H., Zeng, L., Jin, Y., Nie, K., Deng, L., and Wang, F. (2019). "Effect of different carbon sources on cellulase production by marine strain Microbulbifer hydrolyticus IRE-31-192," Appl. Biochem. Biotech. 188(3), 741-749. DOI: 10.1007/s12010-01802948-1

Liu, H., Zhang, S., Yu, N., Dou, L., Deng, L., Wang, F., and Tan, T. (2018). "Direct utilization of non-pretreated hydrolytic liquid of dried distiller's grains with solubles for bio-ethanol by Rhizopus arrhizus RH 7-13-9\#," Appl. Biochem. Biotech. 186, 590596. DOI: $10.1007 / \mathrm{s} 12010-018-2716-4$

Paudel, Y. P., and Qin, W. (2015). "Characterization of novel cellulase-producing bacteria isolated from rotting wood samples," Appl. Biochem. Biotech. 177(5), 11861198.

Payne, C. M., Knott, B. C., Mayes, H. B., Hansson, H., Himmel, M. E., Sandgren, M., Stahlberg, J., and Beckham, G. T. (2015). "Fungal cellulases," Chem. Rev. 115(3), 1308-1448. DOI: $10.1021 / \mathrm{cr} 500351 \mathrm{c}$

Schuster, B. G., and Chinn, M. S. (2013). "Consolidated bioprocessing of lignocellulosic feedstocks for ethanol fuel production," Bioenerg. Res. 6(2), 416-435.

DOI: $10.1007 / \mathrm{s} 12155-012-9278-\mathrm{z}$

Silva, C. D. G., and Filho, E. X. F. (2017). "A review of holocellulase production using pretreated lignocellulosic substrates," Bioenerg. Res. 10(2), 592-602.

DOI: 10.1007/s12155-017-9815-x

Singh, S., Dikshit, P. K., Moholkar, V. S., and Goyal, A. (2015). "Purification and characterization of acidic cellulase from Bacillus amyloliquefaciens SS35 for hydrolyzing Parthenium hysterophorus biomass," Environ. Prog. Sustain. Energ. 34(3), 810-818. DOI: 10.1002/ep.12046

Wen, S., Liu, L., Nie, K. L., Deng, L., Tan, T. W., and Fang, W. (2013). "Enhanced fumaric acid production by fermentation of xylose using a modified strain of Rhizopus arrhizus," BioResources 8(2), 2186-2194. DOI: 10.15376/biores.8.2.21862194.

Zhang, H. L., Baeyens, J., Degrève, J., and Cacères, G. (2013). "Concentrated solar power plants: Review and design methodology," Renew. Sust. Energ. Rev. 22, 466481. DOI: $10.1016 /$ j.rser.2013.01.032

Article submitted: July 17, 2020; Peer review completed: August 29, 2020; Revised version received and accepted: September 16, 2020; Published: September 25, 2020. DOI: 10.15376/biores.15.4.8689-8695 